\title{
The Thinking of Constructing the New System of Integrated Development between Transportation and Logistics
}

\author{
Liqin $\mathrm{Li}^{1}$ and Jinou $\mathrm{Li}^{2}$ \\ 1. Guangdong Provincial Transport senior Technical School; Guangzhou China 510520 \\ 2. Guangdong Provincial Communication Group Co.; Guangzhou China 510623
}

Keywords: economic artery; smooth logistics; integration.

\begin{abstract}
The development of economy and technology has brought the rapid development of transportation industry in our country, making China's transportation industry obtain significant progress and achieve the leap-forward development. At present, the artery of traffic is full in our country and has been the important lifeline of economy development in our country. It can say that the development of transportation industry can not only make people's daily traveling convenient and solve their traffic problem, but also promote the smooth of logistics and development of economy. The constant development of logistics has higher demand with the traffic artery, which makes the integration of transportation and logistics have the possibility. Now, network has intruded into people's daily life and played more and more important role in their daily life. As the production of network era, on-line shopping can expand the domestic demand and stimulate economic growth. However, the most important thing in the on-line shopping is logistics problem, and the convenience and smooth of logistics can make network trade more smooth, which can not only enhance people's confidence degree but boost the rapid development of economy. We can know that the development of logistics needs the development off transportation industry, and the convenient transportation can bring smooth logistics so that promoting the rapid development of logistics industry. So we must improve the integration degree of transportation and logistics to construct the new system of integrated development between transportation and logistics, making the mutual promotion of transportation and logistics and combined action on economy development. This paper mainly give a series of practicable measures on the basis of the existing problems in the new system of integrated development between transportation and logistics.
\end{abstract}

\section{Introduction:}

The current society is the information era of technology and economy, so we must master the artery of economy development — the development of transportation, which can help transportation cause make more and more important contribution to economy to promoting the rapid development of economy. Meanwhile, we should take advantage of the technological result to constantly boost the perfect and development of transportation cause and achieve the safe and convenience of logistics transportation. Now, our country has established varieties of traffic artery systems, making the traffic artery distributed around the world vertically and horizontally and constantly providing important rode construction support for the economy construction in our country and transportation support for logistics transportation. However, with the development of economy, the transportation facility construction has not meet the traffic demand of people and appears the phenomenon of traffic jam, which will result in the logistics transportation not timely arriving and cause enormous loss of logistics transportation company. And the occurrence of the problem, not timely arriving of logistics, promotes the transportation cause to be perfected. In conclusion, the development of transportation provides the probability for logistics transportation, and the logistics transportation put forward new demand to the development of transportation cause. 


\section{Integration of Transportation and Logistics}

Along with the development of transportation cause, logistics transportation has become more rapid, convenient and safe. Namely, it is the development of transportation cause that promotes the appearance, rapid development and modern type change of logistics cause. Now, in order to better give play to the advantages of transportation and logistics, our country is constructing the integrated system of transportation and logistics, which also is the inevitable production in the current transportation and logistics development era.

\subsection{The definition of integration of transportation and logistics}

In fact, the integration of transportation and logistics is integrating the transportation cause with logistics cause and makes them mutual affect and promote, double-box hitting and the development of China's development. The development method of traditional transportation cause and logistics cause is single, but the modern integration of transportation and logistics will make them mutual development to promote the development of China's economy business.

\subsection{Effect of integration of transportation and logistics}

As for the effect of integration of transportation and logistics, we can say it from the two aspects: the one hand is the important effect on the transportation cause, the other hand is the significant effect on logistics cause.

Viewing from the aspect of transportation, the integration of transportation and logistics can provide the development direction for the development of traffic cause. In the process of logistics transportation, we can find the problems in the construction of transportation cause and ensure the future development method of transportation cause. For example, the transportation facility system to Tibet and Xinjiang is still not very perfect now, so this will be the future development direction of transportation cause, and constantly promoting the improvement and development of transportation cause.

Viewing from the aspect of logistics, the integration of transportation and logistics makes the transportation and logistics company take the convenient car of transportation cause, reduce the transportation cost of logistics and strengthen the work efficiency of logistics transportation. The convenience of traffic makes the logistics transportation can timely arrive the target place, which can increase the credibility of logistics transportation company to some degree to promote the rapid development of logistics cause.

Therefore, the integrated method of transportation and logistics is a win-win development method, so we must connect the transportation with logistics to make contributions to the development of China's economy together.

\section{The Existing Problems in the Construction of Current Integrated System of Transportation and Logistics}

Along with the development of transportation and logistics, the integration of transportation and logistics has become the inevitable trend. Our country is also constantly establish effective system of transportation and logistics to make the shortcomings of transportation and logistics cause get mutual supplement and achieve the mutual development of transportation and logistics, but there exists some problems in the construction of the integrated system of transportation and logistics in current China.

\subsection{The imperfect of transportation cause network}

The traffic cause in our country in the current stage has gained rapid development, but in the process of logistics transportation, we still can find that the traffic artery cannot extend to some remote districts, which makes the cargo quality of logistics transportation loss and transportation cost increase, so we must make the perfect of traffic network and make traffic network connect each place to promote the mutual development of economy.

\subsection{Loss of combined transportation ability}

The combined transportation ability of railway, highway and air transportation cause in our country is not good, which will increase the cost and difficulty of logistics transportation to some degree, for example, in the transportation process from Xian to Fujian, we adopt single logistics 
transportation method to reduce the efficiency of logistics transportation and increase the transportation difficulty and transportation cost, time cost and capital cost. But our transportation cause severely lack of combined transportation ability of varieties of transportation methods, and single transportation method will reduce the efficiency of logistics transportation company to make the transportation goods not timely arrive. So the single transportation method is not available, and it also is the place that the traffic cause of our country needs to improve and develop, which can enhance the delivering efficiency of logistics company and speed the rapid development of our economy.

\subsection{Not high traffic transportation service ability}

In the process of logistics transportation, not very high traffic transportation service ability makes the goods quality of transportation appear problems. For example, in the transportation progress of some fragile goods, the goods will get damaged in the transportation process due to the problem of traffic transportation service ability and level. As for the logistics transportation company, it will reduce their transportation efficiency and the credibility of logistics transportation company.

\section{How to Make the Construction of Integrated System of Transportation and Logistics}

Through the above mention, we have known that the integrated system of transportation and logistics has significant effect on the economy construction and the existing problems in the integrated system of transportation and logistics of current stage, so we must make endeavor to the establishment of integrated system of transportation and logistics. In order to construct the effective and convenient integrated system of transportation and logistics, we must perfect the traffic line diagram, synthetically apply the transportation method and improve the independent innovation awareness.

\subsection{Strengthen the awareness of independent innovation}

Innovation has been more and more important competitiveness in the present national society, and we should dare to challenge with convention and enhance the innovation awards of transportation cause development, which can make transportation cause constantly develop forward on the original basis. The development of transportation cause and innovation of construction means can make the integrated system of transportation and logistics acquire the rather long-term development. The current traffic cause in our country has gained great development, and only innovation can provide new development direction for the development of transportation cause, making the development of transportation cause gradually step into the perfection. Meanwhile, in the construction process of transportation cause, only possessing the innovation thought can we effectively use the present technological result and make the local construction with traffic artery, also promoting the combined transportation of many kinds of transportation methods.

\subsection{Perfect the traffic artery}

The current transportation cause in our country has gained unprecedented development, and the constant increasing of traffic artery makes that in our country gradually develop to form the network shape and give play to the significant advantages of traffic artery. It not only provides convenience for people's daily traveling, but constantly promotes the development of our logistics transportation cause. However, the traffic artery network has not extended to some poor districts yet, which makes the logistics transportation in these poor districts extremely hard and the transportation cost very high, so we are urgent to perfect and develop traffic artery, which can powerfully boost our economic growth. Network takes important part in people's daily life, so we must apply network to the communication and logistics field, build and perfect the traffic artery network. Only by this way, the logistics transportation company can timely understand the traffic condition of transportation through area, and it is convenient for logistics transportation company to timely make judgement and choose the more effective and economic transportation means.

\subsection{The combined use of communication network}

Viewing from now, the railway transportation, water transportation and air transportation development have gained significant achievement, but these transportation methods are unique, and the relation degree with each other is not enough, and their combined transportation ability is not so good. Therefore, we must enhance the transportation ability of many kinds of transportation methods, 
such as water transportation, railway transportation, and air transportation, which can perfect and develop the transportation cause of our country and enable our domestic traffic transportation constantly to make important contributions to economy development.

\subsection{Enhance the service level of traffic transportation}

In the construction process of integrated system of transportation and logistics, we can find that our domestic service ability and level of transportation in the current stage are not high, which will affect the goods quality of logistics and transportation company. For example, some fragile good will get damaged and this will cause economy loss and goods loss of logistics and transportation company. So we must constantly enhance the service ability and level of transportation, which can guarantee the cargo in the logistics transportation process to be not damaged and avoid causing the property loss of logistics transportation company. Only by this way can be given play to the biggest advantage of transportation to promote the development of logistics transportation cause. In the meantime, as for some goods needing to be transported by the container, we must strictly do the container handling according to the standard, which also is the significant manifestation of enhancing the ability of traffic transportation service ability.

\section{The Future Trend of Establishing the Integrated System of Transportation and Logistics}

Future is inevitableto be the era of technology and network, and the application of technology and network has universality, which will strengthen the relation of traffic transportation and logistics transportation. So the integrated system of transportation and logistics will be inevitableto take the prominent part in the process of economy development, meanwhile, along with the constant introduction of technological result to the transportation field, the integrated system of transportation and logistics in our country will constantly develop towards the scientific, technological and standard direction. And the development of transportation industry will be more applied to the technological result, constantly promoting the smooth development of logistics cause. The integrated degree of transportation and logistics is continuously increasing, and such hitting of combined box can provide Chinese economy development important energy.

\section{Conclusion}

We are in the era net waved by economy and technology now, and the development of economy and technology has promoted the rapid development of transportation industry. However, the development of transportation industry has brought the development of logistics transportation industry, and the development of logistics transportation industry can promote the development of transportation industry, which makes the future develop towards the direction of the integration of transportation and logistics. Convenient transportation can increase the efficiency of logistics transportation and save the cost of logistics transportation. So we must establish the integrated system of transportation and logistics, and the double-boxing hitting of transportation and logistics will make our economy get rapid development. But in the construction process of integrated system of transportation and logistics, we can find that lots of factors affect the transportation efficiency and cost of logistics, such as the imperfect establishment of traffic artery, lack of combining transportation ability and low level of transportation service ability. Thus, we must take the corresponding measures to perfect the integrated system of transportation and logistics to enable the integrated system constantly to make important contribution to economy development.

\section{References}

[1]. Shan Luan. The new system construction of integrated development between transportation and logistics in Henan [J]. Driving park, 2016,(12):35.

[2]. Dengcai He. The construction of new system of integrated development between transportation and logistics [N]. Chinese economic herald, 2016-10-25(A02). 
[3]. Wenqing $\mathrm{Wu}$. The new system construction of integrated development between transportation and logistics in our country [J]. China tendering, 2016,(28):12-14.

[4]. Shang Ding. The construction of index system combing with the transportation system and modern logistics coordination development [J]. Logistics technology, 2016, 04:82-85.

[5]. i Zhang. Construct the enormous traffic and create the main hub to develop the great logistics and quicken constructing the integrated transportation system of modern integrated transportation [J]. China water transport, 2008, 05:60-61.

[6]. Yangcheng Tu, Gaohua Wu, Bo Rao, Yi Xu, Jianmin Wang, Rongjing Gong. The research of the development of modern agricultural logistics_- the thinking of constructing the modern agricultural logistics system in the mountain of Shiyan, Hubei [J]. Anhui agricultural science, 2005, 03:526-527.

[7]. Changqing Shao. Promote the regional economic integration and modern transportation and logistics coordinated development in the process of constructing the market system[J]. City,2013,12:8-12. 